\title{
Parental Obesity and Risk of Autism Spectrum Disorder
}

WHAT'S KNOWN ON THIS SUBJECT: Maternal prepregnancy

obesity is associated with an increased risk of neurodevelopmental disorders in children, but previous studies have not taken paternal obesity into account. This has precluded differentiation between the effects of intrauterine exposures and potential genetic associations.

\section{WHAT THIS STUDY ADDS: Robust associations were}

demonstrated between paternal obesity and the risk of autistic disorder and Asperger disorder in children. This study is the first to implicate paternal obesity as a risk factor for autism, and replication is warranted.
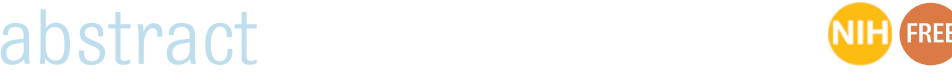

OBJECTIVES: The objective of the study was to investigate the associations among maternal prepregnancy BMI, paternal BMI, and the risk of autism spectrum disorders (ASDs) in children.

METHODS: The study sample of 92909 children was derived from the population-based, prospective Norwegian Mother and Child Cohort Study. The age range was 4.0 through 13.1 (mean 7.4) years. Relative risks of ASDs were estimated by odds ratios (ORs) and $95 \%$ confidence intervals (Cls) from logistic regression models.

RESULTS: At the end of follow-up on December 31, 2012, 419 children in the study sample had been diagnosed with ASDs: 162 with autistic disorder, 103 with Asperger disorder, and 154 with pervasive developmental disorder not otherwise specified. Maternal obesity (BMI 230) was only weakly associated with ASD risk, whereas paternal obesity was associated with an increased risk of autistic disorder and Asperger disorder. The risk of autistic disorder was $0.27 \%$ (25 of 9267) in children of obese fathers and $0.14 \%$ (59 of 41603 ) in children of fathers with normal weight (BMl $<25)$, generating an adjusted OR of 1.73 (95\% Cl: 1.07-2.82). For Asperger disorder, analyses were limited to children aged $\geq 7$ years $(n=50$ 116). The risk was $0.38 \%$ (18 of 4761) in children of obese fathers and $0.18 \%$ (42 of 22 736) in children of normal-weight fathers, and the adjusted OR was 2.01 (95\% Cl: 1.13-3.57). No associations were found for pervasive developmental disorder not otherwise specified.

CONCLUSIONS: Paternal obesity is an independent risk factor for ASDs in children. The associations should be investigated further in genetic and epigenetic studies. Pediatrics 2014;133:e1128-e1138
AUTHORS: Pål Surén, MD, MPH, a,b Nina Gunnes, PhD, a,c Christine Roth, MSc, ${ }^{a, c}$ Michaeline Bresnahan, PhD, ${ }^{\mathrm{c}, d}$ Mady

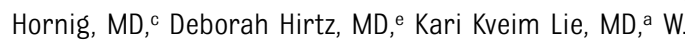
Ian Lipkin, MD, ${ }^{c}$ Per Magnus, MD, PhD, ${ }^{a}$ Ted ReichbornKjennerud, MD, PhD, a,f Synnve Schjølberg, MSc, ${ }^{\text {a Ezra }}$ Susser, MD, DrPH, ,cd Anne-Siri Øyen, PhD, a, George Davey Smith, MD, PhD, ${ }^{\mathrm{h}}$ and Camilla Stoltenberg, MD, PhD ${ }^{\mathrm{a}, \mathrm{i}}$

${ }^{a}$ Norwegian Institute of Public Health, Oslo, Norway; ${ }^{b}$ Centre for Paediatric Epidemiology and Biostatistics, UCL Institute of Child Health, London, United Kingdom; 'Mailman School of Public

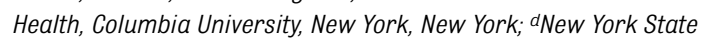
Psychiatric Institute, New York, New York; ${ }^{e}$ National Institute of Neurologic Disorders and Stroke, Bethesda, Maryland; fInstitute of Psychiatry, University of Oslo, Oslo, Norway; ${ }^{\text {Nic Waals }}$ Institute, Lovisenberg Hospital, Oslo, Norway; ${ }^{\text {hMRC Centre for }}$ Causal Analysis in Translational Epidemiology, University of Bristol, Bristol, United Kingdom; and 'Department of Public Health and Primary Health Care, University of Bergen, Bergen, Norway

\section{KEY WORDS}

autism spectrum disorder, autistic disorder, Asperger disorder, PDD-NOS, parental obesity, parental BMI, child cohort study

\section{ABBREVIATIONS}

$A B C$-autism birth cohort

ASD—autism spectrum disorder

$\mathrm{Cl}$-confidence interval

DSM-Diagnostic and Statistical Manual of Mental Disorders

$\mathrm{MoBa}$ - Norwegian Mother and Child Cohort Study

NPR-Norwegian Patient Register

$O R$ - odds ratio

PDD-NOS—pervasive developmental disorder not otherwise specified

PPV—-positive predictive value

Dr Surén was responsible for the conception and design of the study, the analysis and interpretation of data, and the drafting of the manuscript, and he contributed to the acquisition of data; $\mathrm{Dr}$ Gunnes and Ms Roth contributed to the conception and design of the study, participated in the analysis and interpretation of data, and reviewed and revised the manuscript; Drs Bresnahan Hornig, Hirtz, Lie, Lipkin, and Magnus, Ms Schjølberg, and Drs Susser and Øyen contributed to the acquisition of data and the interpretation of results from data analyses and reviewed and revised the manuscript; Drs Reichborn-Kjennerud and DaveySmith provided advice regarding study design, participated in the interpretation of results from data analyses, and reviewed and revised the manuscript; Dr Stoltenberg supervised the study, including the conception and design, the acquisition of data, the analysis and interpretation of data, and the review and revision of the manuscript; and all authors approved the final manuscript as submitted

(Continued on last page) 
Evidence from epidemiologic studies indicates that maternal obesity is a risk factor for neurodevelopmental disorders in children. A case-control study of autism spectrum disorders (ASDs) in California recently demonstrated that mothers who were obese before pregnancy had a $67 \%$ increase in risk of having children with ASDs. ${ }^{1}$ Other studies have found that children of obese mothers have an increased occurrence of attention-deficit/hyperactivity disorder symptoms, ${ }^{2}$ an increased risk of intellectual disability $(I 0<70),{ }^{3}$ lower mean scores on cognitive testing, ${ }^{4}$ and a higher risk of schizophrenia later in life. ${ }^{5}$ The association between maternal prepregnancy obesity and child cognition is not consistent across studies; some studies have found no such associations. ${ }^{6}$

It is commonly assumed that the harm to the child is caused by unfavorable effects of maternal obesity on the intrauterine environment. However, previous studies have not been designed to differentiate between intrauterine exposures and genetic associations, because the father's BMI has not been taken into account. This study sought to expand on previous knowledge by investigating the relative risks of ASDs in children associated with both maternal and paternal BMI, using data from a longitudinal, prospective pregnancy cohort, the Norwegian Mother and Child Cohort Study (MoBa). ${ }^{7}$

\section{METHODS}

\section{Study Population and Outcome Information}

The MoBa cohort is nationwide and includes 109000 children born from 1999 to 2009. Mothers were recruited at ultrasound examinations at approximately week 18 of pregnancy, and $38.5 \%$ of the invited women consented to participation. Cases of ASDs (autistic disorder, Asperger disorder, and pervasive developmental disorder not otherwise specified [PDD-NOS]) have been identified by a substudy of autism, the Autism Birth Cohort (ABC) Study. ${ }^{8}$ The modes of case identification were (1) questionnaire screening of mothers at offspring ages 3, 5, and 7 years; (2) professional and parental referrals of children suspected of having ASD; and (3) linkage to the Norwegian Patient Register (NPR). ${ }^{9}$ The NPR collects data on diagnoses from all hospitals and outpatient clinics in Norway, thereby capturing data for all children diagnosed with ASDs by Norwegian specialist health services. ${ }^{9}$ The analyses in this study reflect data collected and processed by December 31, 2012. The children eligible for analyses were MoBa participants recorded to be alive and living in Norway beyond 3 years of age.

When a child with ASD or potential ASD was detected through any of these mechanisms, he or she was invited to participate in a clinical assessment that included the research-standard instruments for diagnosis of ASDs, the Autism Diagnostic Interview-Revised, ${ }^{10}$ and the Autism Diagnostic Observation Schedule, ${ }^{11}$ which have shown high reliability and validity in making diagnoses of ASDs in children. Diagnostic conclusions were best-estimate clinical diagnoses derived from test and interview results and from information collected from parents and teachers. The diagnoses were based on Diagnostic and Statistical Manual of Mental Disorders (DSM), Fourth Edition, Text Revision criteria, and the case definition includes codes 299.00 (autistic disorder), 299.80 (Asperger disorder), and 299.80 (PDD-NOS). ${ }^{12}$

The NPR contains International Classification of Diseases, 10th Revision codes determined by Norwegian specialist health services, and the ASD case definition of this study includes codes F84.0 (childhood autism), F84.1 (atypical autism), F84.5 (Asperger syndrome), F84.8 (other pervasive developmental disorder), and F84.9 (pervasive developmental disorder, unspecified). In this article, we have used the terms "autistic disorder" for code F84.0 and "PDD-NOS" for codes F84.1, F84.8, and F84.9.

Participation in MoBa and the ABC Study is based on written informed consent from the mother. Both studies are approved by the regional committee for medical and health research ethics for Southeastern Norway.

\section{Exposure Information}

Maternal and paternal height and weight were recorded in a questionnaire completed by the mothers during week 18 of pregnancy. Maternal prepregnancy BMI and paternal BMI were calculated by dividing weight in kilograms by height in meters squared. Weight categories were defined according to World Health Organization

TABLE 1 Cumulative Incidence of ASDs by Year of Birth

\begin{tabular}{lccccr}
\hline Year of birth & No. of children & \multicolumn{1}{c}{ ASD } & Autistic Disorder & Asperger Disorder & PDD-NOS \\
\cline { 3 - 6 } & & $n(\%)$ & $n(\%)$ & $n(\%)$ & $n(\%)$ \\
\hline $1999-2000$ & 1842 & $14(0.76)$ & $1(0.05)$ & $10(0.54)$ & $3(0.16)$ \\
2001 & 3622 & $26(0.72)$ & $7(0.19)$ & $10(0.28)$ & $9(0.25)$ \\
2002 & 7563 & $65(0.86)$ & $21(0.28)$ & $23(0.30)$ & $21(0.28)$ \\
2003 & 11111 & $85(0.77)$ & $32(0.29)$ & $27(0.24)$ & $26(0.23)$ \\
2004 & 12053 & $58(0.48)$ & $19(0.16)$ & $14(0.12)$ & $25(0.21)$ \\
2005 & 13925 & $57(0.41)$ & $22(0.16)$ & $11(0.08)$ & $24(0.17)$ \\
2006 & 15783 & $53(0.34)$ & $24(0.15)$ & $6(0.04)$ & $23(0.15)$ \\
2007 & 14729 & $28(0.19)$ & $13(0.09)$ & $1(0.01)$ & $14(0.10)$ \\
2008 & 12281 & $33(0.27)$ & $23(0.19)$ & $1(0.01)$ & $9(0.07)$ \\
Total & 92909 & $419(0.45)$ & $162(0.17)$ & $103(0.11)$ & $154(0.17)$ \\
\hline
\end{tabular}

Includes cases identified in the study sample by December 31, 2012. 
guidelines as underweight (BMI <18.5), normal weight $(18.5 \leq \mathrm{BMl}<25)$, overweight $(25 \leq \mathrm{BMI}<30)$, and obesity (BMI $\geq 30$ ). ${ }^{13}$ For participants recruited in 2006 and later, paternal height and weight were also recorded in questionnaires completed by the fathers. For those who had both maternal and paternal report of these measures, we carried out a BlandAltman analysis ${ }^{14}$ to assess the agreement between maternal and paternal reporting, and we calculated the $\kappa$ statistic for paternal obesity based on the 2 sources of information.

\section{Covariates}

We explored the following covariates to assess potential confounding and mediation: parental education, parental age, parental smoking, parental psychiatric disorders, maternal parity, maternal use of folic acid supplements, use of hormone treatment or in vitro fertilization to become pregnant, maternal diabetes, preeclampsia, child's year of birth, child's gestational age at birth, and child's birth weight.

\section{Statistical Analyses}

Analyses were performed by using SPSS version 19.0 (IBM SPSS Statistics, IBM Corporation, Armonk, NY) and R version 3.0.2 for Windows (The $R$ Foundation for Statistical Computing, Vienna, Austria). Odds ratios (ORs) of each ASD subtype with $95 \%$ confidence intervals (Cls) were estimated from logistic regression models. We fitted 2 types of adjusted models, 1 in which maternal and paternal BMI were included separately (Model A), and 1 in which both were included simultaneously (Model B). All covariates were examined separately. If the inclusion of a covariate changed any of the relative risk estimates by $>2 \%$, the covariate was included in the final adjusted models.

To explore potential nonlinear effects of maternal and paternal BMI, generalized
TABLE 2 Parent and Child Characteristics by Parental Obesity (BMI $\geq 30$ )

\begin{tabular}{|c|c|c|c|}
\hline Characteristics & $\begin{array}{l}\text { Total Study Sample } \\
\quad(n=92909)\end{array}$ & $\begin{array}{l}\text { Maternal Prepregnancy } \\
\mathrm{BMI} \geq 30 \quad(n=8936)\end{array}$ & $\begin{array}{l}\text { Paternal BMI } \\
\geq 30(n=9267)\end{array}$ \\
\hline \multicolumn{4}{|c|}{ Maternal education, y, $n$ (\%) } \\
\hline$<12$ & $6864(7.4)$ & $1075(12.0)$ & $1031(11.1)$ \\
\hline 12 & 25037 (26.9) & $3365(37.7)$ & $3215(34.7)$ \\
\hline $13-16$ & $37683(40.6)$ & 3212 (35.9) & $3435(37.1)$ \\
\hline$\geq 17$ & $21427(23.1)$ & $1112(12.4)$ & $1392(15.0)$ \\
\hline Missing data & $1898(2.0)$ & $172(1.9)$ & $194(2.1)$ \\
\hline \multicolumn{4}{|c|}{ Paternal education, y, $n$ (\%) } \\
\hline$<12$ & $9908(10.7)$ & $1511(16.9)$ & $1489(16.1)$ \\
\hline 12 & $35330(38.0)$ & 4419 (49.5) & $4340(46.8)$ \\
\hline $13-16$ & 24672 (26.6) & $1809(20.2)$ & $2045(22.1)$ \\
\hline$\geq 17$ & 20687 (22.3) & $982(11.0)$ & $1159(12.5)$ \\
\hline Missing data & $2312(2.5)$ & $215(2.4)$ & $234(2.5)$ \\
\hline \multicolumn{4}{|l|}{ Maternal age, y, $n$ (\%) } \\
\hline$<25$ & $10132(10.9)$ & $1053(11.8)$ & $1089(11.8)$ \\
\hline $25-29$ & $30730(33.1)$ & $2865(32.1)$ & $3123(33.7)$ \\
\hline $30-34$ & $36033(38.8)$ & $3343(37.4)$ & $3405(36.7)$ \\
\hline$\geq 35$ & $16014(17.2)$ & $1675(18.7)$ & $1650(17.8)$ \\
\hline \multicolumn{4}{|l|}{ Paternal age, y, $n$ (\%) } \\
\hline$<25$ & $4370(4.7)$ & $423(4.7)$ & $413(4.5)$ \\
\hline $25-29$ & 21039 (22.6) & $1923(21.5)$ & $1975(21.3)$ \\
\hline $30-4$ & $36087(38.8)$ & 3345 (37.4) & $3531(38.1)$ \\
\hline $35-39$ & $22059(23.7)$ & $2230(25.0)$ & $2330(25.1)$ \\
\hline 40 & 9202 (9.9) & $989(11.1)$ & $1011(10.9)$ \\
\hline Missing data & $152(0.2)$ & $26(0.3)$ & $7(0.1)$ \\
\hline \multicolumn{4}{|l|}{$\begin{array}{l}\text { Maternal smoking during } \\
\text { pregnancy, } n(\%)\end{array}$} \\
\hline No & $84682(91.1)$ & $7811(87.4)$ & $8280(89.3)$ \\
\hline Yes & $7597(8.2)$ & 1062 (11.9) & $938(10.1)$ \\
\hline Missing data & $630(0.7)$ & $63(0.7)$ & $49(0.5)$ \\
\hline \multicolumn{4}{|l|}{ Paternal smoking, $n$ (\%) } \\
\hline No & 66459 (71.5) & $5948(64.2)$ & $6376(68.8)$ \\
\hline Yes & $25237(27.2)$ & $2881(31.1)$ & $2768(29.9)$ \\
\hline Missing data & $1213(1.3)$ & $107(1.2)$ & $123(1.3)$ \\
\hline \multicolumn{4}{|l|}{ Maternal parity, ${ }^{\text {a }} n(\%)$} \\
\hline 0 & $41814(45.0)$ & 3513 (39.3) & $3881(41.9)$ \\
\hline 1 & $33142(35.7)$ & 3384 (37.9) & $3437(37.1)$ \\
\hline$\geq 2$ & 17953 (19.3) & 2039 (22.8) & $1949(21.0)$ \\
\hline \multicolumn{4}{|c|}{$\begin{array}{l}\text { Maternal periconceptional } \\
\text { folic acid use, }{ }^{\mathrm{b}} n(\%)\end{array}$} \\
\hline No & $28451(30.6)$ & $3182(35.6)$ & $3077(33.2)$ \\
\hline Yes & $64458(69.4)$ & $5754(64.4)$ & $6190(66.8)$ \\
\hline \multicolumn{4}{|l|}{$\begin{array}{l}\text { In vitro fertilization, } \\
n(\%)\end{array}$} \\
\hline No & 90066 (96.9) & 8665 (97.0) & 8915 (96.2) \\
\hline Yes & $2843(3.1)$ & $271(3.0)$ & $352(3.8)$ \\
\hline \multicolumn{4}{|l|}{$\begin{array}{l}\text { Maternal hormone } \\
\text { treatment, } n(\%)\end{array}$} \\
\hline No & $90218(97.1)$ & $8486(95.0)$ & $8919(96.2)$ \\
\hline Yes & $2691(2.9)$ & $450(5.0)$ & $348(3.8)$ \\
\hline \multicolumn{4}{|l|}{$\begin{array}{l}\text { Maternal gestational/ } \\
\text { type } 2 \text { diabetes, } n(\%)\end{array}$} \\
\hline No & $91975(99.0)$ & 8631 (96.6) & $9111(98.3)$ \\
\hline Yes & $934(1.0)$ & $305(3.4)$ & $156(1.7)$ \\
\hline \multicolumn{4}{|c|}{ Maternal preeclampsia, ${ }^{c} n(\%)$} \\
\hline No & 89140 (95.9) & 8159 (91.3) & $8772(94.7)$ \\
\hline Yes & $3769(4.1)$ & $777(8.7)$ & $495(5.3)$ \\
\hline \multicolumn{4}{|l|}{$\begin{array}{l}\text { Maternal psychiatric } \\
\text { disorder, }{ }^{d} n(\%)\end{array}$} \\
\hline No & 83172 (89.5) & 7938 (88.8) & $8263(89.2)$ \\
\hline Yes & $9737(10.5)$ & $998(11.2)$ & $1004(10.8)$ \\
\hline \multicolumn{4}{|l|}{ Child's birth wt, $n$ (\%) } \\
\hline$<2500 \mathrm{~g}$ & $3913(4.2)$ & $430(4.8)$ & $443(4.8)$ \\
\hline
\end{tabular}


TABLE 2 Continued

\begin{tabular}{|c|c|c|c|}
\hline Characteristics & $\begin{array}{l}\text { Total Study Sample } \\
\quad(n=92909)\end{array}$ & $\begin{array}{l}\text { Maternal Prepregnancy } \\
\mathrm{BMI} \geq 30 \quad(n=8936)\end{array}$ & $\begin{array}{c}\text { Paternal BMl } \\
\geq 30(n=9267)\end{array}$ \\
\hline 2500-4499 g & 84879 (91.4) & $7730(86.5)$ & $8258(89.1)$ \\
\hline$\geq 4500 \mathrm{~g}$ & $4062(4.4)$ & $772(8.6)$ & $562(6.1)$ \\
\hline Missing data & $55(0.1)$ & $4(0.0)$ & $4(0.0)$ \\
\hline \multicolumn{4}{|c|}{$\begin{array}{l}\text { Premature birth } \\
\text { (gestational age <37 wk) }\end{array}$} \\
\hline No & $86708(93.3)$ & 8155 (91.3) & $8564(92.4)$ \\
\hline Yes & $5833(6.3)$ & $741(8.3)$ & $670(7.2)$ \\
\hline Missing data & $368(0.4)$ & $40(0.4)$ & $33(0.4)$ \\
\hline \multicolumn{4}{|l|}{ Obesity of coparent } \\
\hline No $(\mathrm{BMI}<30)$ & $83642(90.0)$ & $6672(74.7)$ & $7003(75.6)$ \\
\hline Yes (BMI $\geq 30)$ & $9267(10.0)$ & $2264(25.3)$ & $2264(24.4)$ \\
\hline \multicolumn{4}{|l|}{ Parental height $(\mathrm{cm})$} \\
\hline $\begin{array}{c}\text { Mean maternal } \\
\text { height, }(95 \% \mathrm{CI})\end{array}$ & $\begin{array}{l}168.11 \\
\quad(168.07-168.15)\end{array}$ & $\begin{array}{l}167.55 \\
\quad(167.43-167.68)\end{array}$ & $\begin{array}{l}168.02 \\
\quad(167.90-168.15)\end{array}$ \\
\hline $\begin{array}{l}\text { Mean paternal } \\
\text { height, }(95 \% \mathrm{Cl})\end{array}$ & $\begin{array}{l}181.53 \\
\quad(181.49-181.57)\end{array}$ & $\begin{array}{l}180.95 \\
\quad(180.80-181.09)\end{array}$ & $\begin{array}{l}180.73 \\
\quad(180.59-180.87)\end{array}$ \\
\hline \multicolumn{4}{|c|}{ Child's year of birth, $n(\%)^{\mathrm{e}}$} \\
\hline 1999-2000 & $1842(2.0)$ & $116(6.3)$ & $89(4.8)$ \\
\hline 2001 & $3622(3.9)$ & $291(8.0)$ & $252(7.0)$ \\
\hline 2002 & $7563(8.1)$ & $771(10.2)$ & $662(8.8)$ \\
\hline 2003 & $11111(12.0)$ & $1124(10.1)$ & $1069(9.6)$ \\
\hline 2004 & $12053(13.0)$ & $1243(10.3)$ & $1277(10.6)$ \\
\hline 2005 & $13925(15.0)$ & 1385 (9.9) & $1412(10.1)$ \\
\hline 2006 & $15783(17.0)$ & $1509(9.6)$ & $1656(10.5)$ \\
\hline 2007 & 14729 (15.9) & $1354(9.2)$ & $1545(10.5)$ \\
\hline 2008 & $12281(13.2)$ & $1143(9.3)$ & 1305 (10.6) \\
\hline
\end{tabular}

a Parity including previous miscarriage or abortion after week 12 of pregnancy.

b Folic acid use during the time interval from 4 wk before to 8 wk after the start of pregnancy (defined as the start of gestation)

c Includes cases of HELLP (Hemolysis, Elevated Liver enzymes, Low Platelets) syndrome.

d Past or present anorexia/bulimia, depression, and/or anxiety

e Column 2 is column \%; columns 3 and 4 are row percent.

additive models with a logit-link were fitted in R (mgcr package) using a cubic regression spline with 2 degrees of freedom. The parental BMls were included as continuous terms. The odds ratio scale in each model was centered around and set to 1 on the mean population odds of a given ASD estimated from the specific model. ORs with $95 \%$ Cls were plotted against maternal/ paternal BMI.

\section{RESULTS}

A total of 106958 children were eligible for analyses. Children born in 2009 ( $n=$ 3354) were excluded because of low numbers of identified ASD cases. Of the remaining 103604 children, 10695 had missing data on maternal and paternal height and weight. The distribution of covariates among these study subjects indicated that mean BMl was likely to be somewhat higher for those with missing data and that the data may be missing not at random. Because of this, we chose to exclude them rather than impute the missing BMl values. The final study sample included 92909 children. At the end of follow-up, the age range was 4.0 through 13.1 years (mean 7.4 years). ASDs had been diagnosed in 419 (0.45\%) children: 162 $(0.17 \%)$ with autistic disorder, 103 $(0.11 \%)$ with Asperger disorder, and 154 (0.17\%) with PDD-NOS. The distribution of ASD cases by year of birth is shown in Table 1. One hundred eightytwo (43\%) had been clinically assessed through the ABC Study, and the remaining $237(57 \%)$ had specialistconfirmed diagnoses of ASDs recorded in the NPR. Registry diagnoses of ASDs had a high validity for the autism spectrum as a whole; of 60 registry ASD cases assessed through the ABC Study, 58 were found to meet the DSM (Fourth Edition, Text Revision) criteria for ASDs, generating a positive predictive value (PPV) of $97 \%$ (95\% Cl: $88 \%-100 \%)$. The estimate of PPV was also high for a specific diagnosis of autistic disorder, $85 \%$ (17 of 20) (95\% Cl: 62\%-97\%), but lower for the other ASD subtypes, $36 \%$ (8/22; 95\% Cl: $17 \%-$ $59 \%)$ for Asperger disorder and $56 \%$ (10 of 18 ) (95\% Cl: $31 \%-78 \%)$ for PDDNOS. PPV estimates for the subtype diagnoses should be interpreted with caution because the number of cases in each group was low.

Obesity was equally prevalent in mothers and fathers, with $9.6 \%$ of mothers and $10.0 \%$ of fathers having a BMI $\geq 30$. Overweight was more common in fathers; $45.2 \%$ of fathers were overweight, compared with $22.0 \%$ of mothers. In fathers, the number of underweight individuals was low, and all fathers with BMI $<25$ were included in the same category in the logistic regression analyses. Maternal and paternal BMls were positively correlated, with a Pearson correlation coefficient of 0.23 (with BMls as continuous variables).

There were 30284 children with double report of the father's height and 29976 with double report of the father's weight. The mean difference between maternal and paternal report was $0.0 \mathrm{~cm}$ (SD $1.5 \mathrm{~cm}$ ) for paternal height and -0.3 $\mathrm{kg}($ SD $2.7 \mathrm{~kg}$ ) for paternal weight. The limits of agreement ( $95 \%$ Cls) obtained from the Bland-Altman analysis ${ }^{14}$ were $(-2.9$ to 2.9$) \mathrm{cm}$ for height and $(-5.6$ to $5.0) \mathrm{kg}$ for weight. The $\kappa$ statistic for paternal obesity was 0.91 .

The distribution of maternal and paternal obesity across the categories of potential confounders and mediators is shown in Table 2. In both mothers and fathers, obesity was associated with 
lower levels of education and higher levels of smoking. Obese mothers were less likely to be first-time mothers and to have used periconceptional folic acid supplements, and more likely to have used hormone treatment to become pregnant. They also had a higher risk of type 2 diabetes, gestational diabetes, and preeclampsia, and their children had a higher risk of premature birth (gestational age $<37$ weeks) and of having a birth weight $\geq 4500$ g.

Table 3 shows the results of the logistic regression analyses. These analyses generated different results for the individual ASD subtypes, and we have reported subtype-specific ORs as well as 0 Rs for the entire autism spectrum. The analyses for autistic disorder and
PDD-NOS included the whole study sample. The analyses for Asperger disorder and ASD as a whole included only children born in 1999 to 2005 (aged $\geq 7$ years at the end of follow-up) because few cases of Asperger disorder had been identified among the younger children.

Autistic disorder had been diagnosed in $0.27 \%$ (24 of 8936) of children of obese

TABLE 3 Risk of ASDs According to Maternal and Paternal BMI

\begin{tabular}{|c|c|c|c|c|c|}
\hline \multirow[t]{2}{*}{ BMI Category } & Total Study Sample & With Disorder & Unadjusted Model & $\begin{array}{c}\text { Adjusted Model Aa Maternal and } \\
\text { Paternal BMI Separately }\end{array}$ & $\begin{array}{l}\text { Adjusted Model B }{ }^{\text {a }} \text { Maternal } \\
\text { and Paternal BMI Combined }\end{array}$ \\
\hline & $n$ (Column \%) & $n$ (Row \%) & OR $(95 \% \mathrm{Cl})$ & OR $(95 \% \mathrm{Cl})$ & 0dds OR (95\% Cl) \\
\hline \multicolumn{6}{|c|}{ Autistic disorder $(n=162)$} \\
\hline \multicolumn{6}{|l|}{ Maternal BMI } \\
\hline$<18.5$ & $2855(3.1)$ & $5(0.18)$ & $1.06(0.43-2.61)$ & $0.93(0.38-2.30)$ & $0.95(0.39-2.35)$ \\
\hline $18.5-24.9$ & $60655(65.3)$ & $100(0.16)$ & 1 (Ref) & 1 (Ref) & 1 (Ref) \\
\hline $25.0-29.9$ & $20463(22.0)$ & $33(0.16)$ & $0.98(0.66-1.45)$ & $0.95(0.64-1.41)$ & $0.91(0.60-1.35)$ \\
\hline$\geq 30.0$ & $8936(9.6)$ & $24(0.27)$ & $1.63(1.04-2.55)$ & $1.48(0.94-2.32)$ & $1.34(0.84-2.12)$ \\
\hline \multicolumn{6}{|l|}{ Paternal BMI } \\
\hline$<25.0^{\mathrm{b}}$ & $41603(44.8)$ & $59(0.14)$ & 1 (Ref) & 1 (Ref) & 1 (Ref) \\
\hline $25.0-29.9$ & $42039(45.2)$ & $78(0.19)$ & $1.31(0.93-1.84)$ & $1.32(0.94-1.86)$ & $1.31(0.94-1.85)$ \\
\hline$\geq 30.0$ & $9267(10.0)$ & $25(0.27)$ & $1.91(1.19-3.04)$ & $1.82(1.13-2.92)$ & $1.73(1.07-2.82)$ \\
\hline \multicolumn{6}{|l|}{ PDD-NOS $(n=154)$} \\
\hline \multicolumn{6}{|l|}{ Maternal BMI } \\
\hline$<18.5$ & $2855(3.1)$ & $7(0.25)$ & $1.64(0.76-3.53)$ & $1.44(0.66-3.12)$ & $1.43(0.66-3.10)$ \\
\hline $18.5-24.9$ & 60655 (65.3) & $91(0.15)$ & 1 (Ref) & 1 (Ref) & 1 (Ref) \\
\hline $25.0-29.9$ & $20463(22.0)$ & $42(0.21)$ & $1.37(0.95-1.97)$ & $1.31(0.90-1.89)$ & $1.32(0.91-1.91)$ \\
\hline$\geq 30.0$ & $8936(9.6)$ & $14(0.16)$ & $1.04(0.60-1.83)$ & $0.93(0.52-1.64)$ & $0.94(0.53-1.67)$ \\
\hline \multicolumn{6}{|l|}{ Paternal BMI } \\
\hline$<25.0^{b}$ & $41603(44.8)$ & $71(0.17)$ & 1 (Ref) & 1 (Ref) & 1 (Ref) \\
\hline $25.0-29.9$ & $42039(45.2)$ & $67(0.16)$ & $0.93(0.67-1.30)$ & $0.93(0.67-1.31)$ & $0.93(0.66-1.30)$ \\
\hline$\geq 30.0$ & $9267(10.0)$ & $16(0.17)$ & $1.01(0.59-1.74)$ & $0.96(0.55-1.65)$ & $0.95(0.54-1.65)$ \\
\hline \multicolumn{6}{|c|}{ Asperger Disorder ${ }^{c}(n=95)$} \\
\hline \multicolumn{6}{|l|}{ Maternal BMl } \\
\hline$<18.5$ & $1543(3.1)$ & $5(0.32)$ & $2.02(0.81-5.07)$ & $1.92(0.76-4.83)$ & $1.89(0.75-4.77)$ \\
\hline $18.5-24.9$ & 32384 (64.6) & $52(0.16)$ & 1 (Ref) & 1 (Ref) & 1 (Ref) \\
\hline $25.0-29.9$ & 11259 (22.5) & $25(0.22)$ & $1.38(0.86-2.23)$ & $1.38(0.85-2.23)$ & $1.33(0.82-2.15)$ \\
\hline$\geq 30.0$ & $4930(9.8)$ & $13(0.26)$ & $1.64(0.90-3.02)$ & $1.61(0.87-2.98)$ & $1.40(0.74-2.64)$ \\
\hline \multicolumn{6}{|l|}{ Paternal BMI } \\
\hline$<25.0^{\mathrm{b}}$ & $22736(44.4)$ & $42(0.18)$ & 1 (Ref) & 1 (Ref) & 1 (Ref) \\
\hline $25.0-29.9$ & $22619(45.1)$ & $35(0.15)$ & $0.84(0.54-1.31)$ & $0.86(0.55-1.35)$ & $0.85(0.54-1.33)$ \\
\hline$\geq 30.0$ & 4761 (9.5) & $18(0.38)$ & $2.05(1.18-3.57)$ & $2.14(1.22-3.75)$ & $2.01(1.13-3.57)$ \\
\hline \multicolumn{6}{|l|}{$\operatorname{ASD}^{\mathrm{C}}(n=305)$} \\
\hline \multicolumn{6}{|l|}{ Maternal BMI } \\
\hline$<18.5$ & $1543(3.1)$ & $13(0.84)$ & $1.55(0.88-2.72)$ & $1.39(0.79-2.46)$ & $1.39(0.79-2.46)$ \\
\hline $18.5-24.9$ & 32384 (64.6) & $177(0.55)$ & 1 (Ref) & 1 (Ref) & 1 (Ref) \\
\hline $25.0-29.9$ & 11259 (22.5) & $81(0.72)$ & $1.32(1.01-1.72)$ & $1.29(0.99-1.69)$ & $1.26(0.96-1.65)$ \\
\hline$\geq 30.0$ & $4930(9.8)$ & $34(0.69)$ & $1.26(0.87-1.83)$ & $1.17(0.81-1.70)$ & $1.09(0.74-1.59)$ \\
\hline \multicolumn{6}{|l|}{ Paternal BMI } \\
\hline$<25.0^{\mathrm{b}}$ & $22736(44.4)$ & $131(0.58)$ & 1 (Ref) & 1 (Ref) & 1 (Ref) \\
\hline $25.0-29.9$ & $22619(45.1)$ & $130(0.57)$ & $1.00(0.79-1.28)$ & $0.99(0.78-1.27)$ & $1.00(0.78-1.28)$ \\
\hline$\geq 30.0$ & $4761(9.5)$ & $44(0.92)$ & $1.61(1.15-2.28)$ & $1.55(1.10-2.19)$ & $1.53(1.07-2.17)$ \\
\hline
\end{tabular}

Total sample for autistic and disorder, $n=92$ 909; total sample for Asperger disorder and ASD, $n=50116$. Ref, reference category.

a Adjusted for parental education levels, child's year of birth, and maternal parity. For parental education levels, missing data were included as a separate category.

b Underweight (BMl < 18.5) was not used as a separate category for fathers because only $216(0.2 \%)$ had BMl $<18.5$.

${ }^{c}$ Analyses for Asperger disorder and autism spectrum disorder included children aged $\geq 7$ y (children born 1999-2005). ASD includes all subtypes (autistic disorder, PDD-N0S, Asperger's disorder). 
mothers, compared with $0.16 \%$ (100 of $60655)$ of children of normal-weight mothers. The unadjusted analyses indicated an increase in risk associated with maternal prepregnancy obesity, but this increase was substantially attenuated by adjustment for covariates and paternal BMI. The model including paternal BMI (Model B) generated an adjusted OR of 1.34 (95\% Cl: 0.84-2.12) of autistic disorder for children of obese mothers. There was a stronger and more robust association between paternal obesity and children's risk of autistic disorder. In children of obese fathers, the proportion with autistic disorder was $0.27 \%$ (25 of 9267), compared with $0.14 \%$ (59 of 41603 ) in children whose fathers had normal weight. The adjusted $\mathrm{OR}$ of autistic disorder was 1.73 (95\% Cl: 1.07-2.82) for children of obese fathers (Model B). There was no evidence of interaction between maternal and paternal obesity based on the likelihood ratio test of nested models ( $P=.58$ ).

Neither maternal nor paternal BMI was associated with the risk of PDD-NOS in children (Table 3). The association between maternal obesity and Asperger disorder appeared to be similar to that for autistic disorder (Table 3), although the $95 \% \mathrm{Cls}$ included 1 in all models. The association with paternal obesity was stronger and more robust: Asperger disorder had been diagnosed in $0.38 \%$ (18 of 4761 ) of children of obese fathers, compared with $0.18 \%$ (42 of 22 736) of normal-weight fathers, generating an adjusted OR of 2.01 (95\% Cl: 1.13-3.57) (Model B). Again, no interaction was evident between maternal and paternal obesity $(P=.47)$.

The increase in risk associated with paternal obesity was still present when all ASD subtypes were analyzed as a single outcome (Table 3), with an adjusted OR of 1.53 (95\% Cl: 1.07-2.17) of ASDs for children of obese fathers (Model B).

Potential dose-response effects of maternal and paternal BMI were explored in generalized additive models. The results are displayed in Figs 1, 2, 3, and

\section{Unadjusted Model}

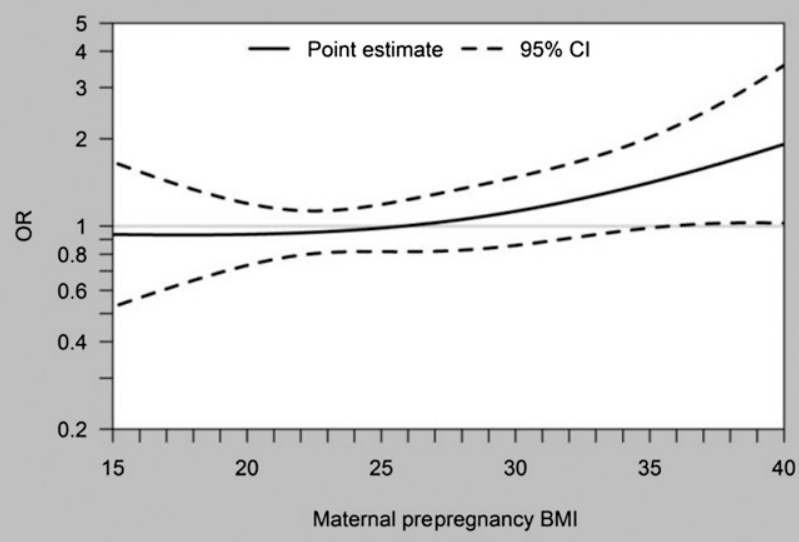

Unadjusted Model

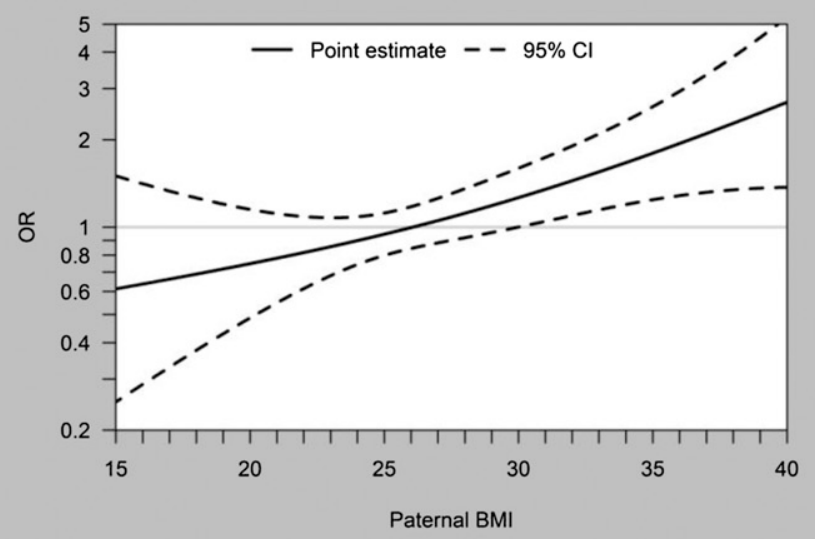

Adjusted Model

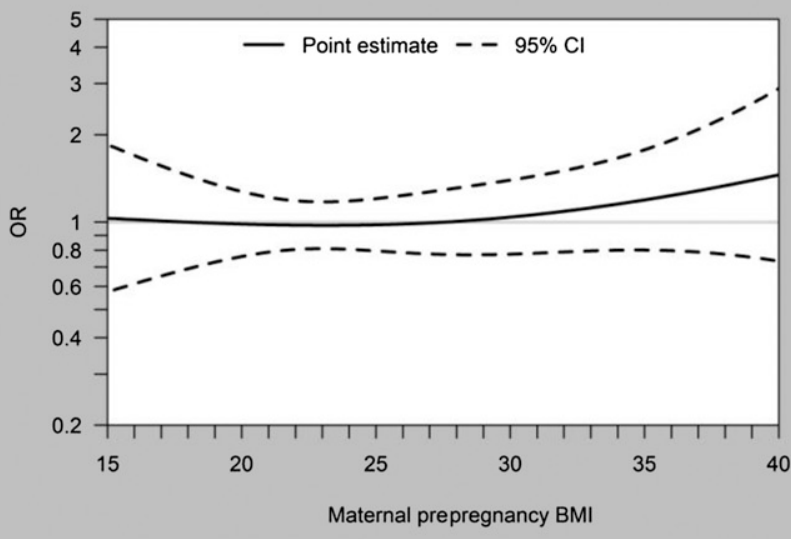

Adjusted Model

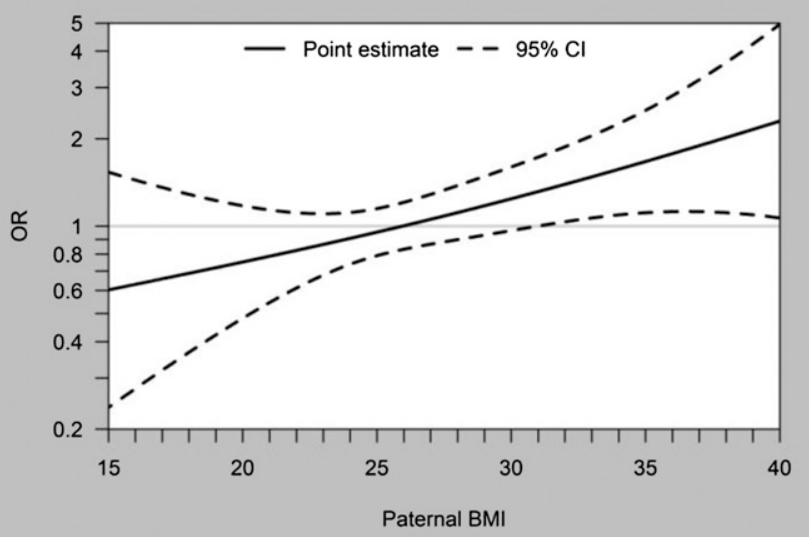

\section{FIGURE 1}

Risk of autistic disorder according to maternal and paternal BMls: generalized additive models. In the adjusted models, maternal and paternal BMls were adjusted for each other and for parental education levels, child's year of birth, and maternal parity. 
4. For maternal BMI, the unadjusted models suggested a continuous increase in odds of autistic disorder and Asperger disorder by increasing BMI for $\mathrm{BMl}$ values $>25$, but this was attenuated by adjustment for covariates and paternal BMI. In contrast, there was an exponential increase in odds of autistic disorder with increasing paternal BMI through the whole range of BMI values, and this association was largely unaffected by adjustment for covariates and maternal BMI. The 95\% $\mathrm{Cl}$ was $>1$ for paternal $\mathrm{BMI}>30$. There was also a continuous increase in risk of Asperger disorder by paternal BMI for $\mathrm{BMI}$ values $>27$, but the $95 \% \mathrm{Cl}$ included 1 throughout.

\section{DISCUSSION}

The main finding of this study was that children of obese fathers have an increased risk of developing autistic disorder and Asperger disorder. The analyses showed that a dose-response relation may be present, so that the risks of these 2 disorders increase by increasing paternal BMI. The associations were largely unaffected by adjustment for sociodemographic and lifestyle characteristics. Our finding came as a surprise because we had expected maternal obesity to be the most prominent risk factor. Maternal obesity was also associated with an increased risk of both autistic disorder and Asperger disorder in unadjusted analyses, but the increase was substantially attenuated by adjustment for paternal BMI.

The previously mentioned study from California found an OR of 1.67 (95\% Cl: 1.10-2.56) of ASDs for children of obese mothers. ${ }^{1}$ We did not replicate this association for ASDs as a whole, but it is worth noting that we obtained $O R$ estimates of a similar magnitude in the models for autistic disorder and Asperger disorder that only included maternal BMI. The attenuation caused by adjustment for paternal BMI in our analyses indicates that paternal BMI is an important confounder of the

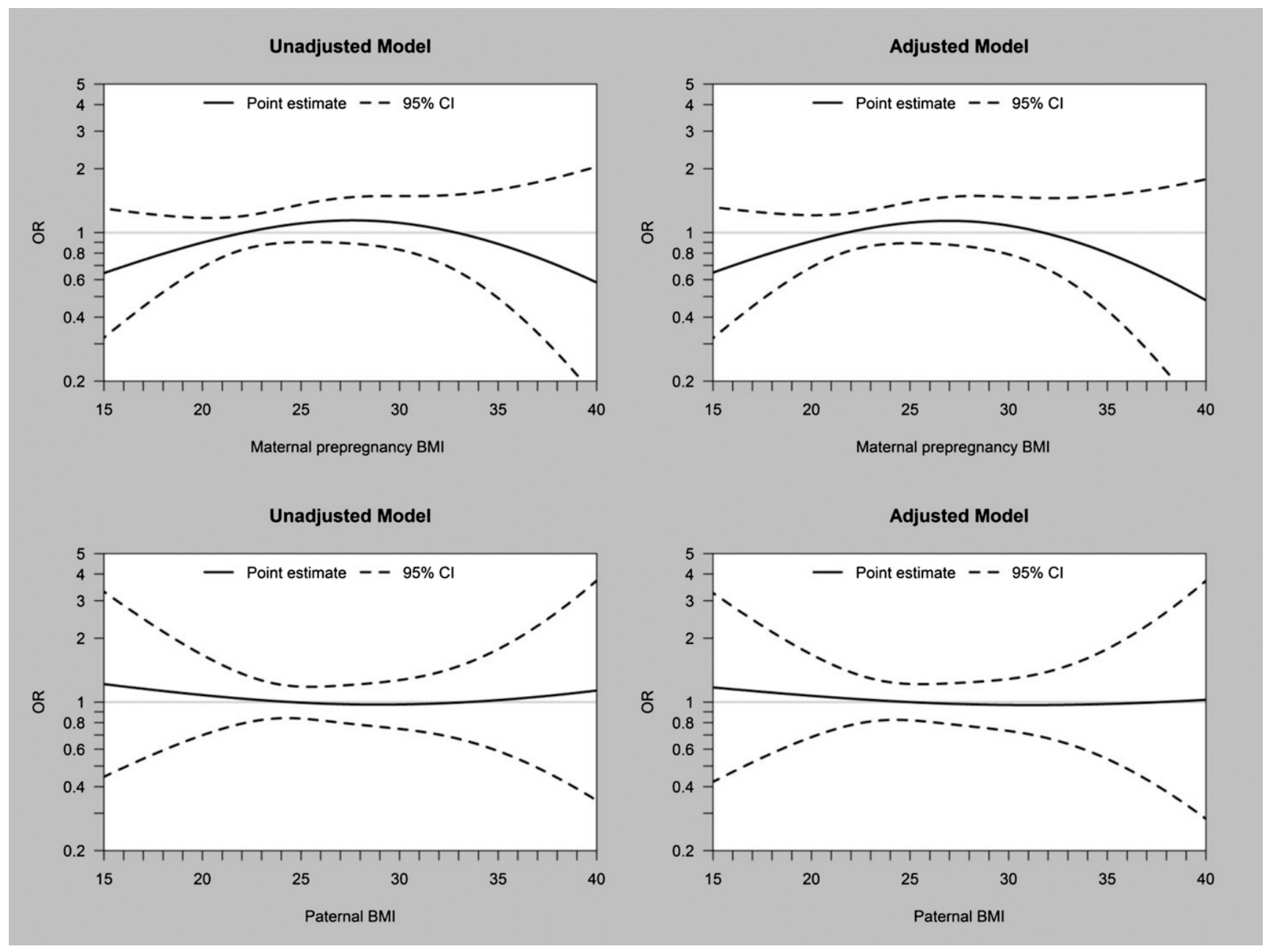

FIGURE 2

Risk of PDD-NOS according to maternal and paternal BMls: generalized additive models. In the adjusted models, maternal BMI and paternal BMls were adjusted for each other and for parental education levels, child's year of birth, and maternal parity. 


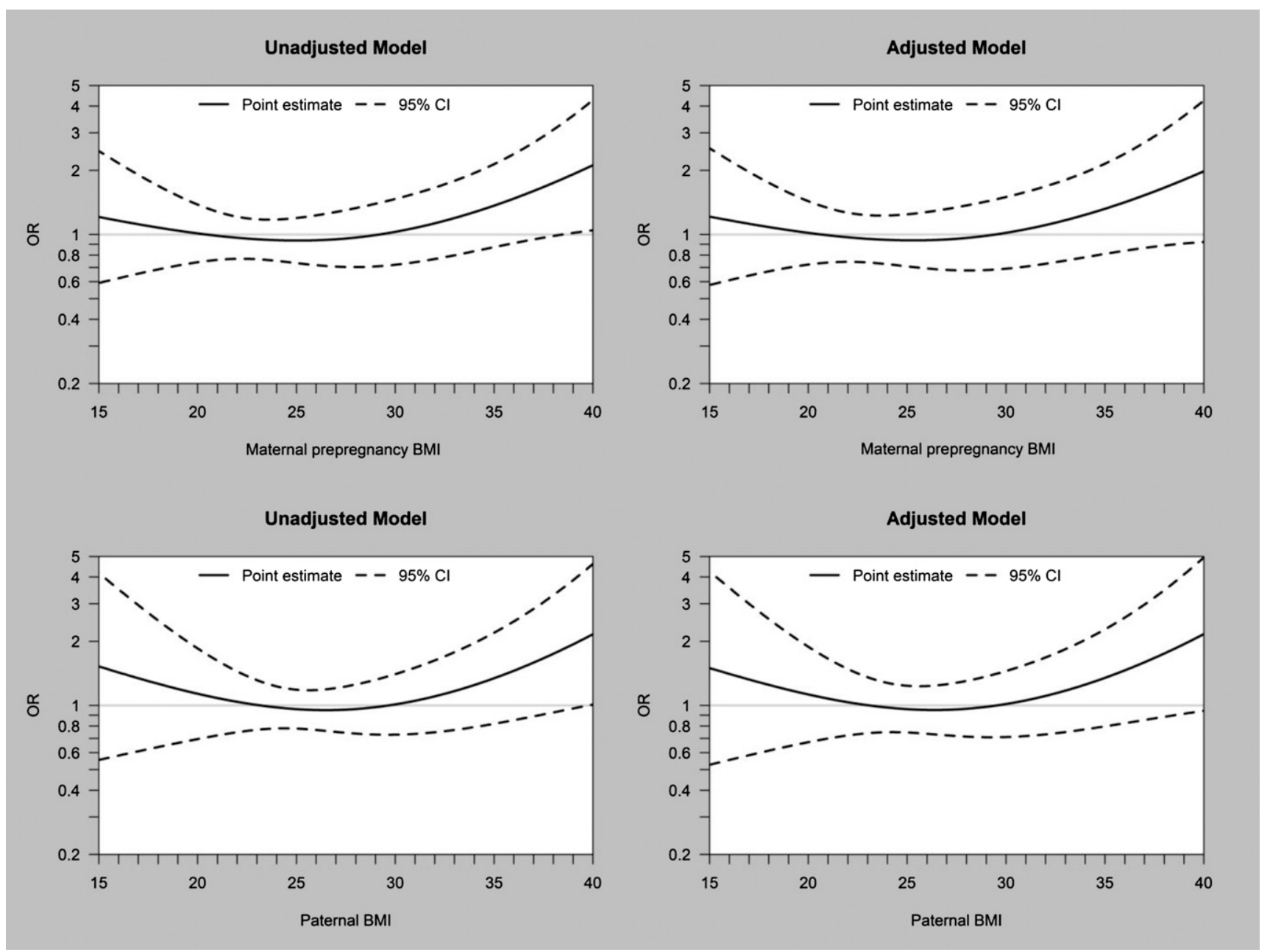

\section{FIGURE 3}

Risk of Asperger disorder according to maternal and paternal BMls: generalized additive models. In the adjusted models, maternal and paternal BMls were adjusted for each other and for parental education levels, child's year of birth, and maternal parity.

association between maternal obesity and ASD risk in children.

No previous studies of maternal obesity and childhood neurodevelopmental disorders have taken paternal BMl into account, and this may have caused an overestimation of the risk associated with maternal obesity. It may also have led researchers to attribute increases in risk to intrauterine exposures only and to overlook alternative explanations. The strong associations observed for paternal obesity in our study sample suggest that there could be a genetic association between paternal obesity and ASDs. Such an association could be mediated through pleiotropic gene variants, that is, gene variants associated with different disorders or traits that have variable manifestations. Examples of such pleiotropic gene variants are the deletions on chromosome 16p11.2 that have been implicated in both ASDs and morbid obesity. ${ }^{15,16}$ If pleiotropic genetic effects were to explain our findings, those gene variants would have to be transmitted from the fathers. Genetic studies have indicated such parent-of-origin effects for other susceptibility loci in ASDs, ${ }^{17-19}$ and parent-of-origin effects have also been demonstrated for other types of complex diseases such as breast cancer, basal cell carcinoma, and type 2 diabetes. ${ }^{20}$ This mode of risk transmission would also be compatible with the gender-specific genetic effects on BMl that have been demonstrated in twin studies. ${ }^{21}$

Another possible mode of risk transmission is through epigenetic alterations caused by paternal obesity, for example, obesity-induced changes in DNA methylation or other mechanisms regulating gene expression. It is still largely unknown whether the epigenetic features of human germline cells are affected by obesity or other environmental exposures, ${ }^{22}$ but it has been demonstrated that children of obese fathers display changes in the expression of genes regulating early growth. ${ }^{23}$ Animal studies have also shown that paternal obesity has transgenerational effects and 


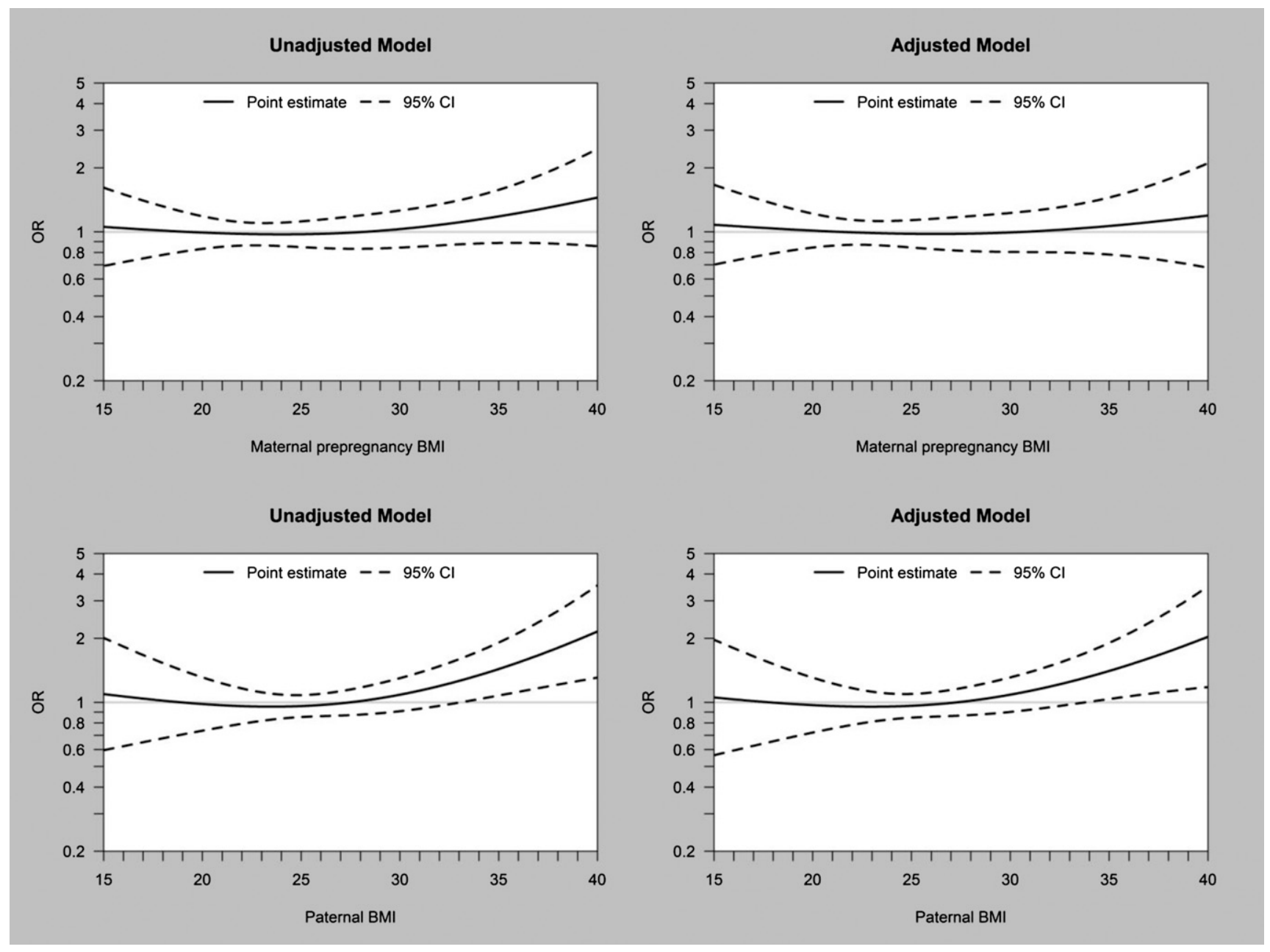

\section{FIGURE 4}

Risk of ASD according to maternal and paternal BMls: generalized additive models. In the adjusted models, maternal and paternal BMls were adjusted for each other and for parental education levels, child's year of birth, and maternal parity.

that those effects are likely to be mediated through epigenetic mechanisms. ${ }^{24}$

We did not find any associations for the PDD-NOS subtype of ASD. PDD-NOS does not have any specific diagnostic criteria, but it is used as a subthreshold category for children who have some autistic features but not sufficient to meet the specific diagnostic criteria for autistic disorder or Asperger disorder. The PDD-NOS subtype encompasses a heterogeneous group of children in our study sample, ranging from children with congenital syndromes and profound mental retardation to high-functioning children with milder symptoms of autism. The fact that the associations with paternal obesity were observed only for autistic disorder and Asperger's disorder indicates that they cannot entirely be attributed to residual confounding; if residual confounding was substantial, we would have expected to find associations across all ASD subtypes.

The main limitation of the study was that the self-reported height and weight measures for the parents have not been validated through objective measurements. However, data from 2 contemporary British and Dutch pregnancy cohorts indicate that pregnant women generally report their own height and weight accurately; correlations between self-reported and objectively measured BMls in pregnant women were 0.97 and 0.96 , respectively. ${ }^{6}$ No similar validation data are available for fathers, but the high level of agreement between maternal and paternal report in our study sample supports the accuracy of the self-reported paternal measures.

The other main limitation was the reliance on subtype diagnoses of ASDs. ASD subtype diagnoses have not been found to have high reliability across assessment sites in the United States, ${ }^{25}$ and the division into subtypes has been removed altogether from the just-released DSM-5 classification system. ${ }^{26}$ Still, our analyses for ASD as a whole showed that the association for paternal obesity, which was the most prominent finding, persisted even when subtype diagnoses were ignored. 
There is an underrepresentation of socially disadvantaged parents in the MoBa cohort, and this may limit the generalizability of our findings. ${ }^{27}$ We have evaluated the potential effects of selection bias in MoBa by analyzing the associations between ASDs and 7 selected exposures in parallel in $\mathrm{MoBa}$ and the general Norwegian population. ${ }^{28}$ The differences were small for all the associations investigated, indicating that exposure-disease associations for ASDs are not substantially affected by selection bias. ${ }^{28}$ This is in line with analyses of other exposure-disease associations from $\mathrm{MoBa}^{27}$ and from contemporary Danish ${ }^{29,30}$ and British ${ }^{31}$ pregnancy cohorts.

\section{REFERENCES}

1. Krakowiak P, Walker CK, Bremer AA, et al. Maternal metabolic conditions and risk for autism and other neurodevelopmental disorders. Pediatrics. 2012;129(5). Available at: www.pediatrics.org/cgi/content/ full/129/5/e1121

2. Rodriguez A, Miettunen J, Henriksen TB, et al. Maternal adiposity prior to pregnancy is associated with ADHD symptoms in offspring: evidence from three prospective pregnancy cohorts. Int $J$ Obesity 2008;32(3):550-557

3. Heikura U, Taanila A, Hartikainen AL, et al. Variations in prenatal sociodemographic factors associated with intellectual disability: a study of the 20-year interval between two birth cohorts in northern Finland. Am J Epidemiol. 2008;167(2):169-177

4. Basatemur E, Gardiner J, Williams C, Melhuish E, Barnes J, Sutcliffe A. Maternal prepregnancy BMI and child cognition: a longitudinal cohort study. Pediatrics. 2013;131(1): 56-63

5. Khandaker GM, Dibben CR, Jones PB. Does maternal body mass index during pregnancy influence risk of schizophrenia in the adult offspring? Obesity Rev. 2012;13(6): 518-527

6. Brion MJ, Zeegers $M$, Jaddoe $V$, et al. Intrauterine effects of maternal prepregnancy overweight on child cognition and behavior in 2 cohorts. Pediatrics. 2011;127 (1). Available at: www.pediatrics.org/cgi/ content/full/127/1/e202
The strengths of the study were the prospective cohort design, large sample size, and the combination of screening, referrals, and registry linkage for detection of ASD cases. Exposure and covariate data were collected in midpregnancy, which minimized the risk of recall bias. Our ability to link the cohort to the nationwide patient registry ensured that all diagnosed cases of ASDs in the study sample were detected, regardless of whether parents had responded to the cohort questionnaires.

\section{CONCLUSIONS}

Our study is the first to implicate paternal overweight and obesity as independent risk factors for ASDs in

7. Magnus P, Irgens LM, Haug K, Nystad W, Skjaerven R, Stoltenberg C; MoBa Study Group. Cohort profile: the Norwegian Mother and Child Cohort Study (MoBa). Int J Epidemiol. 2006;35(5):1146-1150

8. Stoltenberg C, Schjølberg S, Bresnahan M, et al; ABC Study Group. The Autism Birth Cohort: a paradigm for gene-environmenttiming research. Mol Psychiatry. 2010;15 (7):676-680

9. Surén P, Bakken IJ, Aase $\mathrm{H}$, et al. Autism spectrum disorder, ADHD, epilepsy, and cerebral palsy in Norwegian children. Pediatrics. 2012;130(1). Available at: www. pediatrics.org/cgi/content/full/130/1/e152

10. Lord C, Rutter M, Le Couteur A. Autism Diagnostic Interview-Revised: a revised version of a diagnostic interview for caregivers of individuals with possible pervasive developmental disorders. J Autism Dev Disord. 1994;24(5):659-685

11. Lord C, Risi S, Lambrecht L, et al. The autism diagnostic observation schedulegeneric: a standard measure of social and communication deficits associated with the spectrum of autism. J Autism Dev Disord. 2000;30(3):205-223

12. American Psychiatric Association. Diagnostic and Statistical Manual of Mental Disorders. 4th ed, text revision. Arlington, VA: American Psychiatric Association Publishing; 2000

13. World Health Organization. Global Database on Body Mass Index. Available at: http:// children. If the associations were to represent a causal relation, it would have large public health implications, given the increasing prevalence of obesity worldwide. The potential effects should be further investigated through attempts at replication of our analyses, and, if these are positive, through genetic and epigenetic studies. It should also be explored whether paternal overweight and obesity are associated with an increased risk of other neurodevelopmental disorders in children.

\section{ACKNOWLEDGMENTS}

We are grateful to the families in Norway who participate in MoBa and the $\mathrm{ABC}$ Study.

apps.who.int/bmi/index.jsp?introPage=intro_3.html. Accessed April 5, 2013

14. Bland JM, Altman DG. Statistical methods for assessing agreement between two methods of clinical measurement. Lancet. 1986; (8476):307-310

15. Bochukova EG, Huang $N$, Keogh J, et al. Large, rare chromosomal deletions associated with severe early-onset obesity. $\mathrm{Na}$ ture. 2010;463(7281):666-670

16. Walters RG, Jacquemont $S$, Valsesia $A$, et al. A new highly penetrant form of obesity due to deletions on chromosome 16p11.2. Nature. 2010;463(7281):671-675

17. Lamb JA, Barnby G, Bonora E, et al; International Molecular Genetic Study of $\mathrm{Au}$ tism Consortium (IMGSAC). Analysis of IMGSAC autism susceptibility loci: evidence for sex limited and parent of origin specific effects. J Med Genet. 2005;42(2):132-137

18. Arking DE, Cutler DJ, Brune CW, et al. A common genetic variant in the neurexin superfamily member CNTNAP2 increases familial risk of autism. Am J Hum Genet. 2008;82(1):160-164

19. Fradin D, Cheslack-Postava K, Ladd-Acosta $C$, et al. Parent-of-origin effects in autism identified through genome-wide linkage analysis of 16,000 SNPS. PLOS ONE. 2010;5 (9):e12513

20. Kong A, Steinthorsdottir V, Masson G, et al; DIAGRAM Consortium. Parental origin of sequence variants associated with complex diseases. Nature. 2009;462 (7275):868-874 
21. Harris JR, Tambs K, Magnus P. Sex-specific effects for body mass index in the new Norwegian twin panel. Genet Epidemiol. 1995;12(3):251-265

22. Relton CL, Davey Smith G. Is epidemiology ready for epigenetics? Int J Epidemiol. 2012; 41(1):5-9

23. Soubry A, Murphy SK, Wang F, et al. Newborns of obese parents have altered DNA methylation patterns at imprinted genes [published online ahead of print 0ctoer 13, 2013]. Int J Obesity

24. Ng SF, Lin RC, Laybutt DR, Barres R, Owens $J A$, Morris MJ. Chronic high-fat diet in fathers programs $\beta$-cell dysfunction in fe- male rat offspring. Nature. 2010;467(7318): 963-966

25. Lord C, Petkova E, Hus V, et al. A multisite study of the clinical diagnosis of different autism spectrum disorders. Arch Gen Psychiatry. 2012;69(3):306-313

26. American Psychiatric Association. Diagnostic and Statistical Manual of Mental Disorders. 5th ed. Arlington, VA: American Psychiatric Association Publishing; 2013

27. Nilsen RM, Vollset SE, Gjessing HK, et al. Self-selection and bias in a large prospective pregnancy cohort in Norway. Paediatr Perinat Epidemiol. 2009;23(6):597-608

28. Nilsen RM, Surén P, Gunnes N, et al. Analysis of self-selection bias in a population- based cohort study of autism spectrum disorders. Paediatr Perinat Epidemiol. 2013;27 (6):553-563

29. Nohr EA, Frydenberg M, Henriksen TB, Olsen J. Does low participation in cohort studies induce bias? Epidemiology. 2006;17(4):413418

30. Greene N, Greenland S, Olsen J, Nohr EA. Estimating bias from loss to follow-up in the Danish National Birth Cohort. Epidemiology. 2011;22(6):815-822

31. Wolke D, Waylen A, Samara M, et al. Selective drop-out in longitudinal studies and non-biased prediction of behaviour disorders. Br J Psychiatry. 2009;195(3):249-256

\section{(Continued from first page)}

www.pediatrics.org/cgi/doi/10.1542/peds.2013-3664

doi:10.1542/peds.2013-3664

Accepted for publication Feb 6, 2014

Address correspondence to Pål Surén, MD, MPH, Norwegian Institute of Public Health, P0 Box 4404 Nydalen, N-0403 0slo, Norway. E-mail: pal.suren@fhi.no PEDIATRICS (ISSN Numbers: Print, 0031-4005; Online, 1098-4275).

Copyright (C) 2014 by the American Academy of Pediatrics

FINANCIAL DISCLOSURE: The authors have indicated they have no financial relationships relevant to this article to disclose.

FUNDING: MoBa is supported by the Norwegian Ministry of Health and Care Services, the Norwegian Ministry of Education and Research, the Research Council of Norway/FUGE (grant 151918), the National Institute of Neurologic Disorders and Stroke (National Institutes of Health [NIH]/NINDS, Bethesda, MD, grant NS47537 [Lipkin]), and the National Institute of Environmental Health Sciences (NIH/NIEHS, Research Triangle Park, NC, contract NO-ES-75558). The ABC Study is funded by the NINDS (grant NS47537 [Lipkin]). The analyses presented in this article were funded by the Research Council of Norway (grants 185476 and 190694 ). Funded by the National Institutes of Health ( $\mathrm{NIH})$

POTENTIAL CONFLICT OF INTEREST: The authors have indicated they have no potential conflicts of interest to disclose. 